Mini Review

\title{
The Preparation and Electroanalytical Investigation of Lubricants: a Mini Review
}

\author{
Liang Cheng, ${ }^{1, *}$ Zhihua Zhang ${ }^{1}$, Jun Y $u^{2}$, Jie Zhang ${ }^{l}$ and Jing Sun ${ }^{1}$ \\ ${ }^{1}$ College of Chemical Engineering, Guangdong University of Petrochemical Technology, \\ Maoming, 525000, People's Republic of China \\ ${ }^{2}$ Shenzhen Xinyifang Biotechnology Co., Ltd. Shenzhen, 518000, People's Republic of China \\ *E-mail: frankcheng001664@163.com
}

doi: $10.20964 / 2019.11 .45$

Received: 17 July 2019 / Accepted: 21 August 2019 / Published: 7 October 2019

Lubricants play a very important role in industry. Different lubricants were synthesized for different working conditions. In this mini-review, we first introduced various synthesis methods for different types of lubricant preparation. Some of our works were included and discussed. Then, electroanalyticalbased characterization techniques were summarized.

Keywords: Electroanalytical-based property; Lubricant; Preparation; Tribology

\section{FULL TEXT}

(C) 2019 The Authors. Published by ESG (www.electrochemsci.org). This article is an open access article distributed under the terms and conditions of the Creative Commons Attribution license (http://creativecommons.org/licenses/by/4.0/). 